\title{
Structure Characterization of Terazosin Drug using Mass Spectrometry and Thermal Analyses Techniques in Comparison with Semi-Empirical Molecular Orbital (MO) Calculations
}

\author{
M.A. Zayed", M.A. Fahmey", M.El-Desawy" and Yasmeen S. Farrag \\ Chemistry Department, Faculty of Science, Cairo University, \\ 12613- and Nuclear Physics Department, Nuclear Research \\ Centre, Atomic Energy Authority, 13759-Cairo, Egypt.
}

\begin{abstract}
T ERAZOSIN $\left(\mathrm{C}_{19} \mathrm{H}_{25} \mathrm{~N}_{5} \mathrm{O}_{4}, M W=387\right)$ drug is a selective alpha 1 antagonist. It is used for lowering the blood pressure. Also, it is used for treatment of symptoms of an enlarged prostate, and is therefore a drug of choice for men with hypertension and prostate enlargement. In the present study, mass spectrometry (MS) and thermal analyses (TA) were used to investigate the fragmentation decomposition pathways of terazosin and confirmed by semiempirical molecular orbital (MO) calculation, using PM3 procedure on the neutral and the positively charged species of the drug. These calculations included, bond length, bond order, partial charge distribution, ionization energy and heats of formation $\left(\Delta \mathrm{H}_{\mathrm{f}}\right)$. The mass spectra and thermal analyses fragmentation pathways were proposed and compared to each other to select the most suitable scheme representing the correct fragmentation pathway of the drug in both techniques. This selection helps understanding the metabolism of the drug in vivo system. Therefore, comparison between MS and TA helps in selection of the proper pathway representing the fragmentation of this drug. This comparison was successfully confirmed by MO-calculation.
\end{abstract}

Keywords: Terazosin, Mass and spectrometry, Thermal analysis, Molecular orbital calculation and PM3.

Terazosin hydrochloride $\left(\mathrm{C}_{19} \mathrm{H}_{25} \mathrm{~N}_{5} \mathrm{O}_{4}\right)$ drug (marketed ITRIN), has an IUPAC name; 2-[4-(2-tetrahydrofuranyl) carbonyl]-1-piperazinyl- 6, 7-dimethoxy-4quinazolinamine monohydrochloride dihydrate and its stereo structure is given in Fig.1.

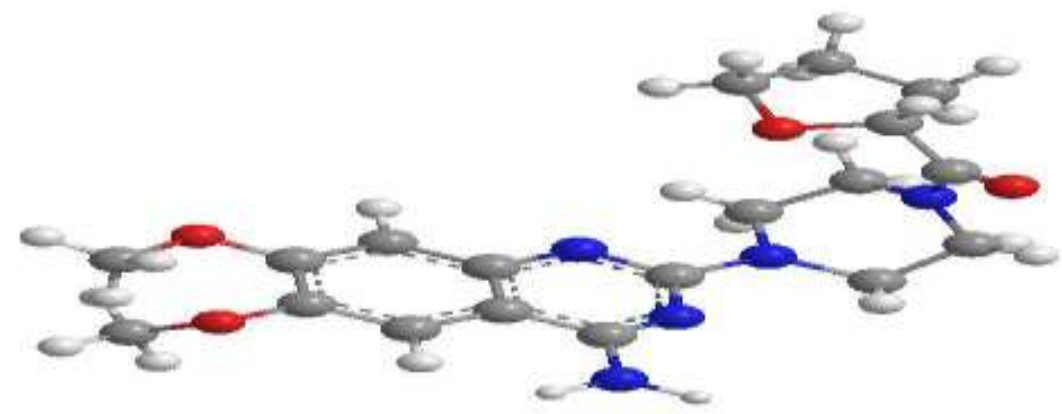

Fig .1. The geometrical structure of Terazosin (Tera).

${ }^{\#}$ Corresponding Author: e-mail: mazayed429@yahoo.com, Tel: 002-02-22728437,002-01005776675, Fax: 002-02-35727556. 
It is a highly selective potent $\alpha-1$ adrenoreceptor antagonist. It is an effective drug for hypertension and prostatic hyperplasia. Terazosin relaxes muscles in the prostate and bladder neck, making it easier to urinate ${ }^{(1)}$.

Mass spectrometry (MS) and thermal analysis (TA) are two physical methods of analysis that are often times used in parallel with each other ${ }^{(2-6)}$. The complementary nature of these techniques has been demonstrated for some species where the fragmentation and/or subsequent degradation processes began at a similar location within the molecule, i.e. the weaker bond. In MS, the species are ionized, where ions of increased stability is detected. In TA, the species are heated until they decompose yield mass losses until the sample is completely decomposed.

Mass spectrometry has become a powerful tool for drug metabolism studies ${ }^{(4)}$. The technique is important because it provides a large amount of structural information with little expenditure of sample. In electron impact (EI) mass spectrum, the fragmentation consists of series of competitive and consecutive unimolecular fragmentation ${ }^{(5)}$. The fragmentation of ionized molecule depends mainly on their internal energy ${ }^{(6)}$. At $70 \mathrm{eV}$ the spectra are very complex; it is difficult to uncover all the competing and consecutive fragmentation reaction.

By lowering the energy of the ionized electron beam it is possible to make the spectra more simple and the high energy processes are thus suppressed ${ }^{(7) .}$.

Thermal analytical techniques can provide important information regarding storage and stability of pharmaceuticals. Thermal analytical methods have thus become important tools for the development of modern medicines ${ }^{(8-12)}$. These are precise and accurate techniques with low sample requirements, and can provide detailed information about new chemical entities even at the very earliest stages of discovery and development of the new compositions and drugs ${ }^{(13-16)}$. Thermogravimetric TG/DTG analysis is used to provide quantitative information on weight losses due to decomposition and /or evaporation of low molecular materials as a function of time and temperature. In conjunction with mass spectrometric analysis ${ }^{(17-19)}$, the nature of the released volatilize may be deduced, thus greatly facilitating the interpretation of thermal degradation processes. On the other hand, computational quantum chemistry can provide additional information about the atoms and bonds, which can be used successfully in an interpretation of experimental results ${ }^{(20)}$. Application of computational quantum chemistry in addition to experimental results (MS and TA) gives valuable information about the atoms and bonds which helps in the description and prediction of primary fragmentation site of cleavage and subsequent one ${ }^{(21-24)}$.

Some analytical methods have been previously reported for determination of terazosin in biological fluids and pharmaceutical preparations. Terazosin was determined by spectroscopic method ${ }^{(2)}$, fluorimetry ${ }^{(3)}$, high-performance liquid

Egypt. J. Chem. 58, No. 3 (2015) 
chromatography (HPLC) with fluorescence detection ${ }^{(4)}$, HPLC ${ }^{(5)}$, x-ray fluorescence spectrometry based on the formation of ion-pair associates with zinc thiocyanate ${ }^{(6)}$

The aim of the present work is focusing on further application of our previous work on various drugs ${ }^{(21-24)}$. This work includes a correlation between, mass spectral fragmentation and thermal analysis degradation of the terazosin drug and comparing these experimental data with the theoretical MO-calculation to identify the weakest bonds ruptured during both mass and thermal studies consequently the choice of the correct pathway of such fragmentation. Knowing this structural session of bonds can be used to decide the active sites of this drug responsible for its chemical, biological and medical reactivity in vivo system.

\section{Experimental}

\section{Molecular orbital calculations (MOCS)}

The MOCS were performed using semi-empirical molecular orbital calculation. The method used in these computations is the parametric method (PM-3) described by Stewart ${ }^{(25)}$. The default criteria for terminating all optimizations were increased by a factor of 100 (keyword PRECISE). Vibrational frequencies were computed for the studied structures (keyword FORCE) so as to check whether the newly designed geometries are local minima. All the molecular orbital calculations were carried out at the Restricted Hartree-Fock level (RHF) for the neutral molecule of terazosin while the Unrestricted Hartree-Fock level (UHF) was carried out for its cation by using PM-3 method followed by full optimization of all geometrical variables (bond lengths, bond angles, and dihedral angles), without any symmetry constraint. All structures were optimized to a gradient norm 0.01-0.05, using the eigenvector following (EF) routine ${ }^{(26)}$. All the semi empirical MO calculations were performed with the MOPAC2000 software package ${ }^{(27)}$ implemented on an Intel Pentium IV 3.0 G Hz computer.

\section{Thermal analyses (TA)}

The thermal analyses of terazosin drug were made using conventional thermal analyzer (Shimadzu system of DTG-60H). The mass losses of $2.161 \mathrm{mg}$ sample and heat reopens of the change of the sample were measured from room temperature up to $800{ }^{\circ} \mathrm{C}$ in nitrogen atmosphere at heating rate $=10^{\circ} \mathrm{C} \mathrm{min}$. These instruments were calibrated using indium metal as a thermal stable material. The reproducibility of the instrument reading was determined by repeating each experiment more than twice.

Mass spectrometry (MS)

Electron Impact (EI) mass spectrum of terazosin is obtained using Thermo Finnegan TRACE DSQ quadruple mass spectrometer with electron multiplier detector equipped with GCMS data system. The direct probe (DP) for solid material was used in this study. The sample was put into a glass sample micro 
vial, by a needle ( $\approx 1 \mu \mathrm{g} \max )$, the vial installed on the tip of the DP containing heating cable and inserted into the evacuated ion source. The sample was ionized by electron beam emitted from the filament, the generated ions being effectively introduced into the analyzer by the focusing and extractor lenses system. The MS was continuously scanned and the obtained spectra were stored. Electron impact mass spectra were obtained at ionizing energy value of 70 and $15 \mathrm{eV}$, ionization current of $60 \mu \mathrm{A}$ and vacuum is better than $10^{-6}$ torr.

\section{Results and Discussion}

It is of great interest to study the chemistry and reactivity of terazosin drug because of its importance in medicine ${ }^{(28)}$. Knowledge obtained from thermal decomposition mechanisms of the neutral drug is very important to understand the chemical process that took part in biological systems ${ }^{(29)}$. It is difficult to establish the exact major fragmentation pathway in EI using conventional MS. With combining the above two techniques and the data obtained from the MO calculation, it is possible to understand the following topics:

1. Stability of the drug under thermal degradation in solid state and mass spectral fragmentation in gas phase.

2. Prediction of the primary site of fragmentation and subsequent bond cleavage.

3. The correct pathway in both techniques.

4. Understanding what actually happened in biodegradation of the drug or its derivatives in vivo system and metabolites.

5. Thermal stability of the drug required information for handling, storage and shelf life.

\section{Computational molecular orbital calculations (MOCS)}

Molecular orbital (MO) calculation gives valuable information about the structure and reactivity of the molecules, actually used to support the experimental evidence. The much important parameters calculated using MO calculation include bond orders, bond length, and charge distribution, heat of formation and ionization energy. In the present work, the calculations have been carried out on terazosin neutral molecule (related to TA decomposition) and charged molecular ion (related to MS fragmentation) which is used for prediction of the weakest bond rupture to follow the fragmentation pathways in both techniques. Figure 2 shows the numbering system of terazosin skeleton that helps in ordering the calculated parameters.

Egypt. J. Chem. 58, No. 3 (2015) 


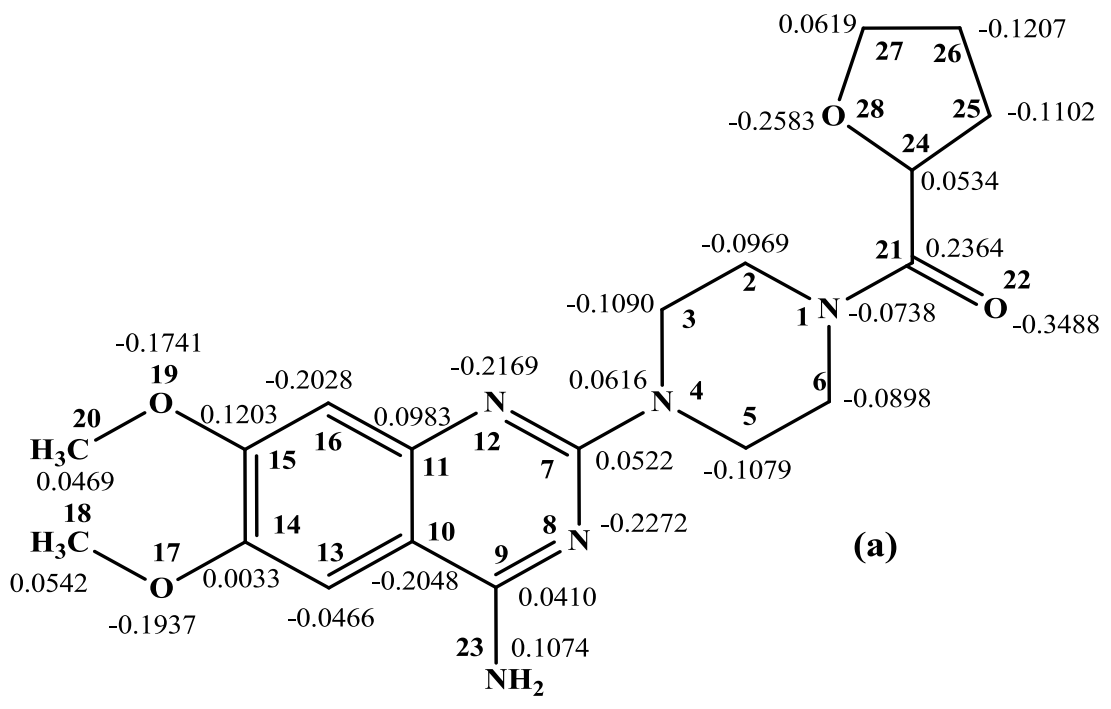

$\Delta H_{\mathrm{f}}[$ Tera $]=-104.85 \mathrm{kcal} \mathrm{mol}^{-1}$

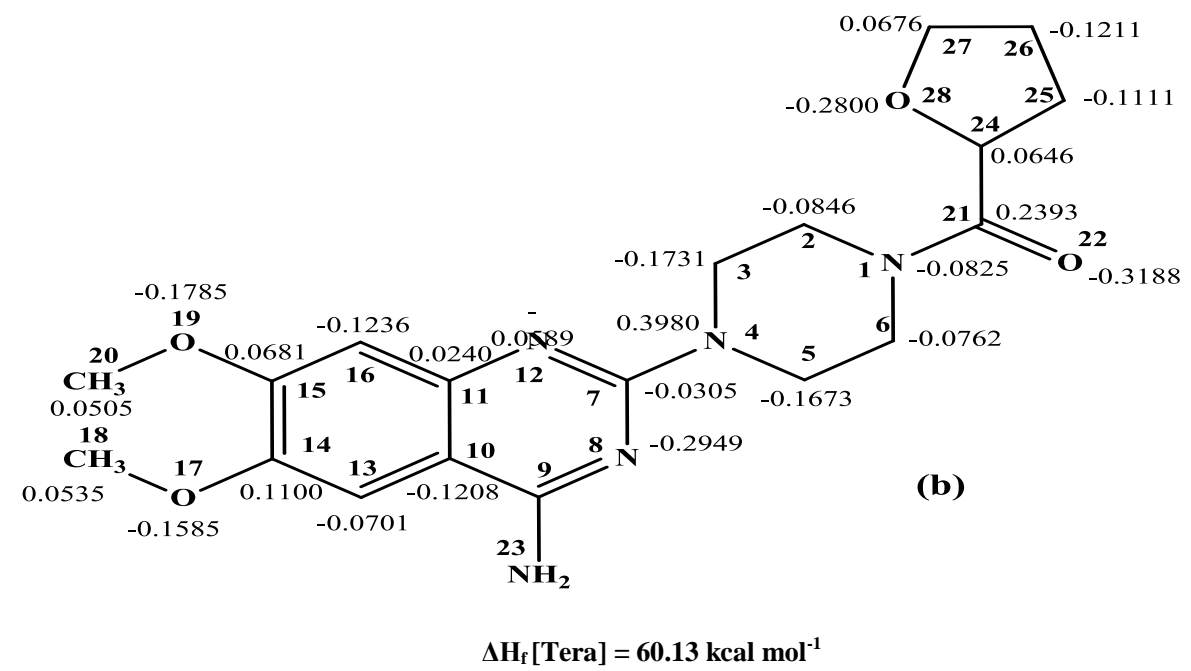

Fig. 2. Charge distribution on different atoms of Tera (a) neutral molecule, (b) molecular ion. 
Table 1 represents the values of bond length $(\AA)$ and bond order.

TABLE 1. Comparison between the computed bond length (in $\AA$ ), and bond order using PM3 method for neutral and molecular cation of terazosin drug.

\begin{tabular}{|r|r|r|r|r|}
\hline \multirow{2}{*}{ Terazosin } & \multicolumn{2}{|c|}{ Bond Length $(\mathbf{A})$} & \multicolumn{2}{c|}{ Bond Order } \\
\cline { 2 - 5 } & Neutral & Cation & Neutral & Cation \\
\hline N1-C2 & 1.490 & 1.482 & 0.966 & 0.977 \\
\hline N1-C6 & 1.491 & 1.484 & 0.967 & 0.975 \\
\hline N1-C21 & 1.442 & 1.452 & 1.032 & 0.991 \\
\hline C2-C3 & 1.531 & 1.534 & 0.972 & 0.964 \\
\hline C3-N4 & 1.489 & 1.488 & 0.972 & 0.964 \\
\hline N4-C5 & 1.490 & 1.488 & 0.968 & 0.962 \\
\hline N4-C7 & 1.423 & 1.366 & 1.103 & 1.376 \\
\hline C5-C6 & 1.531 & 1.533 & 0.973 & 0.965 \\
\hline C7-N8 & 1.397 & 1.390 & 1.185 & 1.190 \\
\hline C7-N12 & 1.349 & 1.402 & 1.470 & 1.143 \\
\hline N8-C9 & 1.344 & 1.358 & 1.501 & 1.373 \\
\hline C9-C10 & 1.439 & 1.461 & 1.131 & 1.038 \\
\hline C9-N23 & 1.406 & 1.357 & 1.155 & 1.400 \\
\hline C10-C11 & 1.412 & 1.437 & 1.312 & 1.147 \\
\hline C10-C13 & 1.413 & 1.387 & 1.240 & 1.409 \\
\hline C11-N12 & 1.389 & 1.358 & 1.221 & 1.374 \\
\hline C11-C16 & 1.419 & 1.425 & 1.231 & 1.186 \\
\hline C13-C14 & 1.377 & 1.415 & 1.563 & 1.300 \\
\hline C14-C15 & 1.437 & 1.440 & 1.177 & 1.157 \\
\hline C14-O17 & 1.392 & 1.360 & 1.008 & 1.094 \\
\hline C15-C16 & 1.381 & 1.391 & 1.524 & 1.434 \\
\hline C15-O19 & 1.375 & 1.371 & 1.052 & 1.057 \\
\hline O17-C18 & 1.411 & 1.410 & 0.973 & 0.960 \\
\hline O19-C20 & 1.408 & 1.410 & 0.983 & 0.969 \\
\hline C21-O22 & 1.219 & 1.215 & 1.836 & 1.872 \\
\hline C21-C24 & 1.541 & 1.540 & 0.901 & 0.898 \\
\hline C24-C25 & 1.538 & 1.535 & 0.970 & 0.973 \\
\hline C24-O28 & 1.425 & 1.426 & 0.980 & 0.977 \\
\hline C25-C26 & 1.528 & 1.528 & 0.986 & 0.985 \\
\hline C26-C27 & 1.530 & 1.528 & 0.983 & 0.984 \\
\hline C27-O28 & 1.423 & 1.425 & 0.970 & 0.961 \\
\hline & & & & \\
\hline
\end{tabular}

The order of bonds strength depending upon the values of bond length and bond order:

C21-C24 (1.541-1.540, 0.901-0.898) < C5-C6 (1.531-1.533, 0.973-0.965) = C2-C3 (1.531-1.534, 0.972-0.964) < C3-N4 (1.489-1.488, 0.972-0.964) < N4-C5 $(1.490-1.488,0.968-0.962)<\mathrm{C} 21-\mathrm{N} 1(1.442-1.452,1.032-0.991)<\mathrm{C} 7-\mathrm{N} 4$ $(1.423-1.366,1.103-1.376)<\mathrm{C} 24-\mathrm{O} 28$ (1.425-1.426, 0.980-0.977), respectively. The weakest bond is that of long bond length and of lowest bond order.

One can conclude the following from Table 1.

1. Small differences in bond length in terazosin system upon ionization, indicating that no appreciable change in the geometries during this variation.

Egypt. J. Chem. 58, No. 3 (2015) 
2. The lowest bond order (important for prediction of primary site of cleavage) observed at bond C21- C24 for both neutral (0.909) and positive species (0.898).

3. Upon ionization of terazosin the stability of the molecule decreased by 164.58 $\left.\mathrm{kcal} \mathrm{mol}{ }^{-1}\left(\Delta \mathrm{H}_{\mathrm{f}}-104.85\right)-\Delta \mathrm{H}_{\mathrm{f}}+(60.13)\right)$.

The charge distribution on different atoms $(\mathrm{C}, \mathrm{N}$ and $\mathrm{O})$ and heats of formation; $\Delta \mathrm{H}_{\mathrm{f}}\left(\mathrm{kcal} \mathrm{mol}^{-1}\right)$ for neutral and ionic terazosin species and the numbering system of the drug are summarized in Fig. 2 (a \& b), respectively. Significant changes in the electron distribution with given system often take place during the ionization. The MOCS data of neutral and ionized forms of terazosin are shown in Table 1 and represent the values of bond length and bond order.

Thermal analyses and mOCS of neutral Tera molecule

The thermal analyses (TA) of terazosin are illustrated in Fig. 3 in which this drug decomposed completely within the temperature range of $21.32-768.55{ }^{\circ} \mathrm{C}$ (mass loss $=89.63 \%$ ).
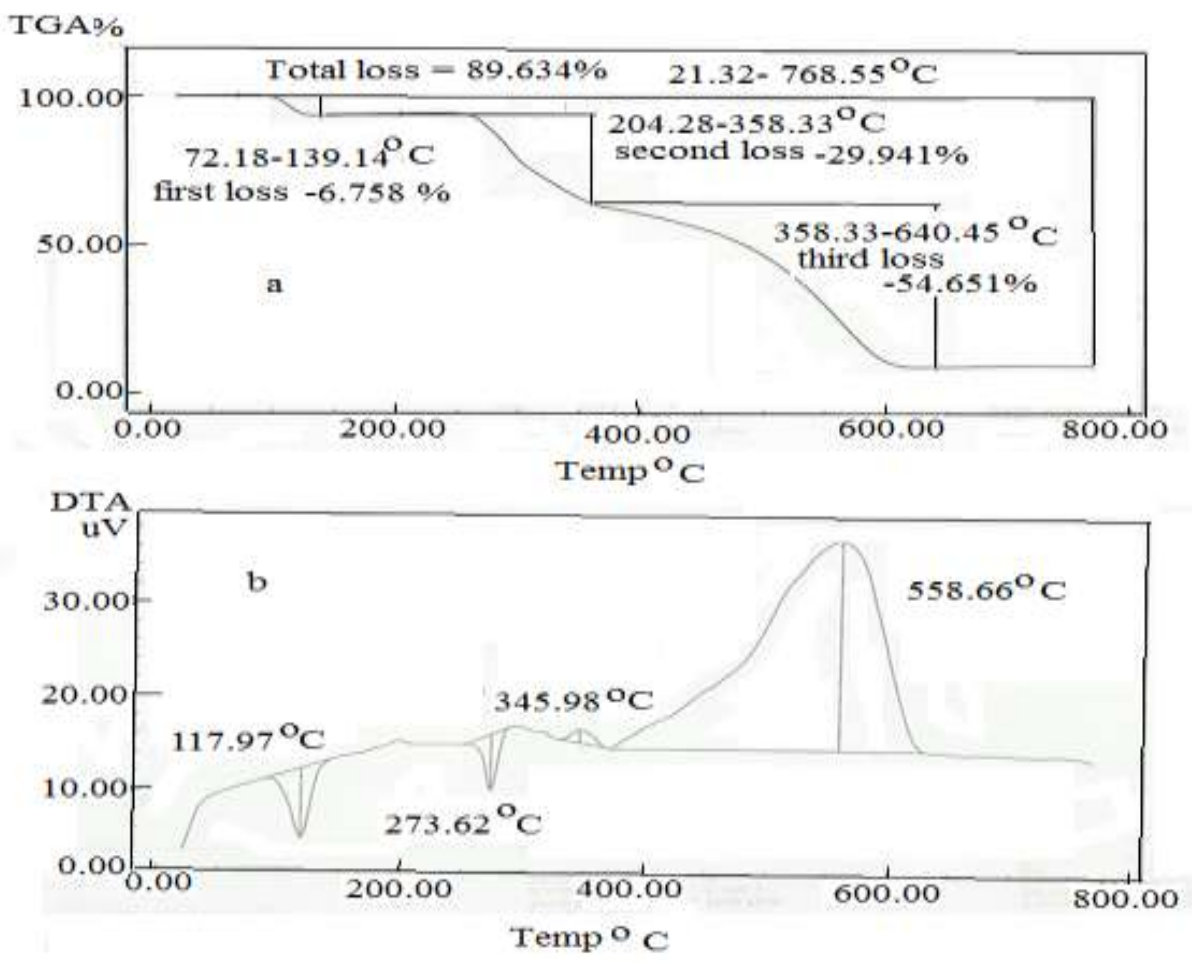

Fig. 3.Thermal analyses of terazosin: a- TGA, b- DTA. 
Figure 3a shows the TG of the drug; it refers to its thermal decomposition in three steps. The first one occurs in the temperature range $72.18-139.14{ }^{\circ} \mathrm{C}$, practical weight loss $=6.758 \%$. It may be related to the loss of two water molecules (estimated weight loss, $=7.83 \%$ ). This weight loss is confirmed by the appearance of endothermic peak in DTA (Fig. 3b) at temperature $117.97{ }^{\circ} \mathrm{C}$. The second one occurs at $204.28-358.33{ }^{\circ} \mathrm{C}$ of practical mass loss $=29.94 \%$; it may be attributed to the loss of $\mathrm{C}_{7} \mathrm{H}_{13} \mathrm{NO}_{2}$, estimated mass loss $=30.66 \%$ as a result of rupture of two weak bonds $\mathrm{C} 3-\mathrm{C} 2$ and $\mathrm{C} 5-\mathrm{C} 6$. This weight loss is confirmed by the appearance of exothermic peak in DTA (Fig. 3b) at temperature 345.98 ${ }^{\circ} \mathrm{C}$. The third weight loss occurs in the temperature range of $358.33-640.45^{\circ} \mathrm{C}$. It may be attributed to the loss of $\mathrm{C}_{10} \mathrm{H}_{11} \mathrm{~N}_{3} \mathrm{O}_{2} \mathrm{HCl}$ (practical weight loss $=54.65 \%$, estimated $=53 \%$ ) as a result of rupture of the weak bond C7-N4. It appears as exothermic peak in DTA at $558.66{ }^{\circ} \mathrm{C}$. An endothermic peak appears in DTA at $273.62{ }^{\circ} \mathrm{C}$, may be due to the melting of Tera, which is acceptable to the value of the reported melting point ${ }^{(30)}$. These peaks may be attributed to chemical fragmentation and rearrangements to give new possible final forms. Therefore, these thermal decomposition endothermic peaks and chemical exothermic rearrangements of thermal decomposition of terazosin can be represented by Scheme 1 .

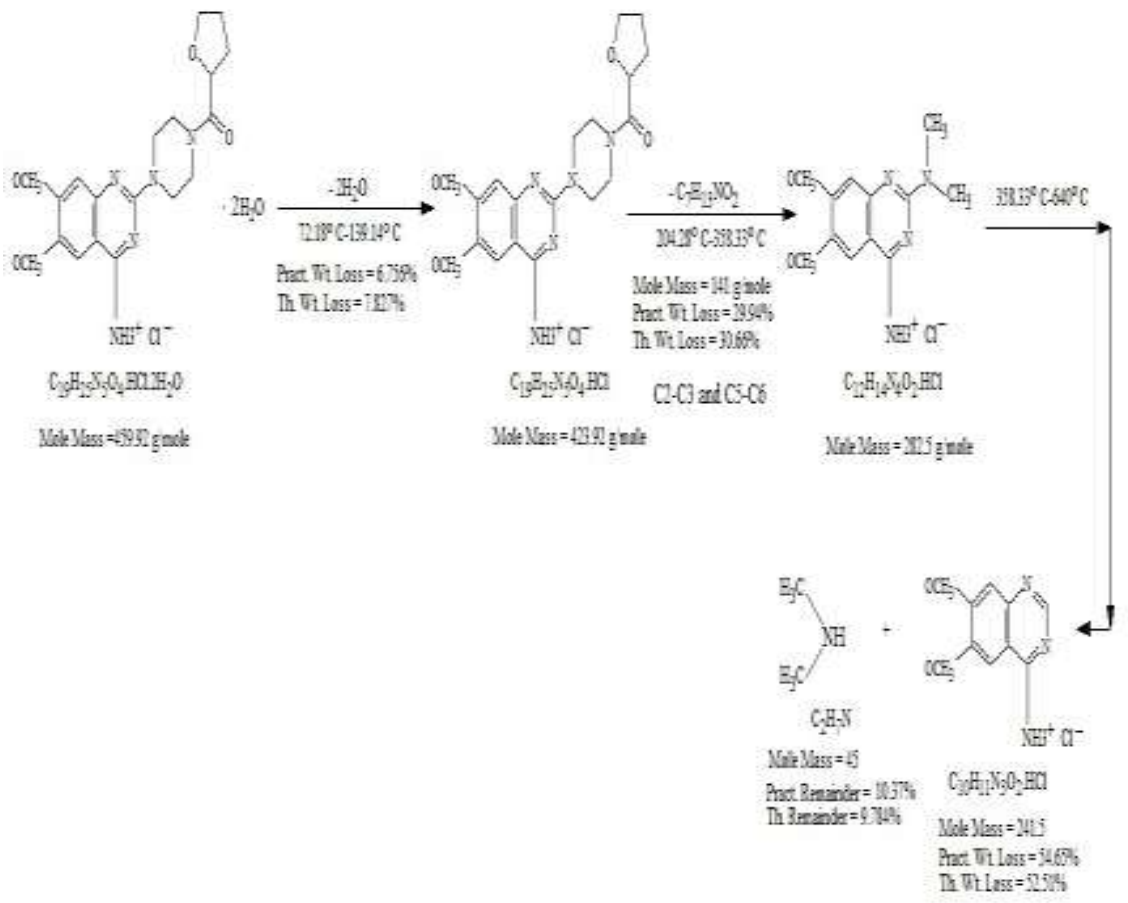

Scheme 1. Thermal decomposition scheme of terazosin.

In this scheme; the ruptured bonds are those thermally unstable as detected by MOCS. These bonds are C3-C2 $(1.531,0.972)<$ C6-C5 $(1.531,0.973)<$ C7-

Egypt. J. Chem. 58, No. 3 (2015) 
N4 $(1.423,1.103)$; which ordered from the weakest to the strongest depending upon the values of bond length and bond order of the neutral form of Tera (Fig. 2a). This order of thermal bond rupture is also correlated with the charge values on atoms of these bonds as given by: C3-C2 (-0.1090, -0.0969) < C6-C5 $(-0.0898,-0.1079)<\mathrm{C} 7-\mathrm{N} 4(0.0522,0.0616)$. The charge values on bond atoms actually affected both bond length or bond order as a result of repulsive or attractive forces between these atoms ${ }^{(29)}$

The thermodynamic calculations from TG data applying Coat-Redfern ${ }^{(29)}$ are given in Table 2.

TABLE 2. Thermodynamic parameters of thermal decomposition of terazosin $\mathrm{HCl}$.

\begin{tabular}{|c|c|c|c|c|c|}
\hline $\begin{array}{l}\text { Decomp. Temp. } \\
\text { Range (K) }\end{array}$ & $\begin{array}{l}\mathbf{E}^{*} \mathbf{K J} \\
\text { mole }^{-1}\end{array}$ & $A\left(S^{-1}\right)$ & $\begin{array}{l}\Delta \mathrm{S} \text { J.K } \\
{ }^{1} \text {.mole }^{-1}\end{array}$ & $\begin{array}{l}\Delta \mathbf{H ~ K J} \\
\mathrm{mole}^{-1}\end{array}$ & $\begin{array}{c}\Delta \mathrm{G} \mathrm{KJ} \\
\mathrm{mole}^{-1}\end{array}$ \\
\hline $345.2-412.1$ & 158.6 & $\begin{array}{c}7.25 \mathrm{x} \\
10^{20}\end{array}$ & 152.3 & 155.4 & 96.4 \\
\hline $477.0-631.5$ & 136.6 & $\begin{array}{c}2.32 \mathrm{x} \\
10^{11}\end{array}$ & -32.65 & 131.9 & 150.4 \\
\hline $631.3-913.5$ & 86.86 & $\begin{array}{c}2.77 \mathrm{x} \\
10^{4}\end{array}$ & -168.48 & 79.98 & 220.90 \\
\hline
\end{tabular}

These data show that three thermal decomposition steps required activation energy values $E^{*}=158.6,136.6,86.86$; enthalpy changes $\Delta H^{*}=155.4,131.9$, 79.98; free energy changes $\Delta \mathrm{G}^{*}=96.4,150.4,220.90$ and entropy values $\Delta \mathrm{S}^{*}=152.3,-32.65,-168.48$, respectively. The order of activation energy, enthalpy and free energy values is in good agreement with bond strength ruptures given by MOCS. The positive entropy value of the first step of decomposition refer to more easier bond rupture, while the negative values refer to stability of consequent bonds ruptured during second and third steps.

These results may help to identify some of possible metabolites of this drug in vivo system.

Mass spectral (MS) fragmentation and MOCS of Terazosin ionized drug molecule

The scope of this investigation is restricted to a search for prediction of the first and subsequent bond ruptures during the course of fragmentation of terazosin drug in MS technique. The subsequent fragmentation in MS is determined to large extent by the initial bond rupture of molecular ion ${ }^{(17-24)}$. A number of mass spectrometric techniques have utilized helping in rationalizing the correct pathways of the molecules, among which are: threshold measurement ${ }^{(31)}$ and metastable abundance ratios ${ }^{(32)}$. On the other hand, computational can provide important information which can be used successfully in description of primary site of cleavage. These theoretical data can be particularly, valuable for MS because they are studied in gas phase species, which can be be handled much more easily by quantum chemistry ${ }^{(25-28)}$. Mass spectral fragmentation of terazosin drug using electron impact mass spectra (EI) and chemical ionization (CI) was

Egypt. J. Chem. 58, No. 3(2015) 
recorded and investigated. Typical mass spectra (bar-graph) of the drug at different energy values are shown in Fig. 4.

Tera $70 \mathrm{eV}$ DIP EI 219201101 \#442 RT: 5.80 AV: 1 SB: $4410.41,0.04 .5 .78$ NL: $1.88 E 6$

$\mathrm{T}:+$ cFull ms $[40.00-420.00]$

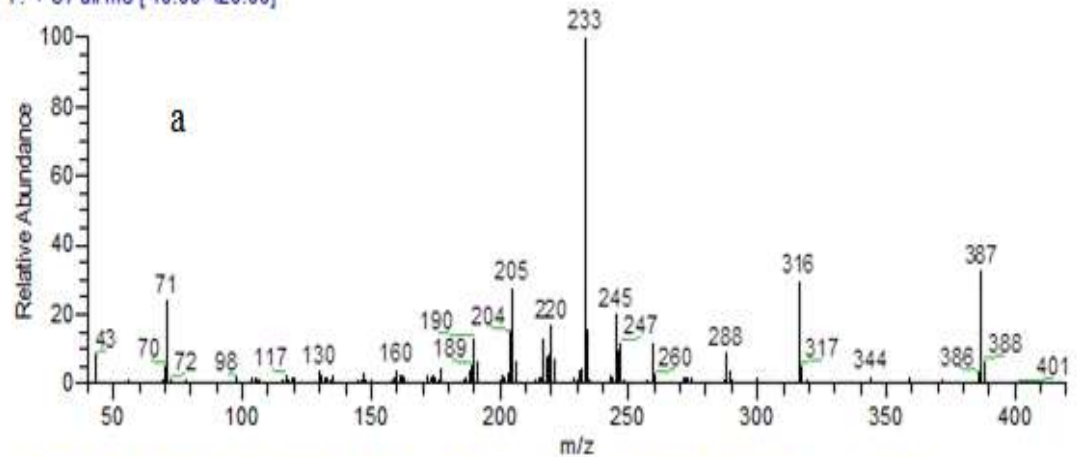

Tera $15 \mathrm{eV}$ EI DIP $219201101 \# 434$ RT: 5.70 AV: 1 SB: $4240.04-5.55,1.03$ NL: $1.07 E 8$ $T_{i}+$ e F ull ms $[40.00-420.00]$

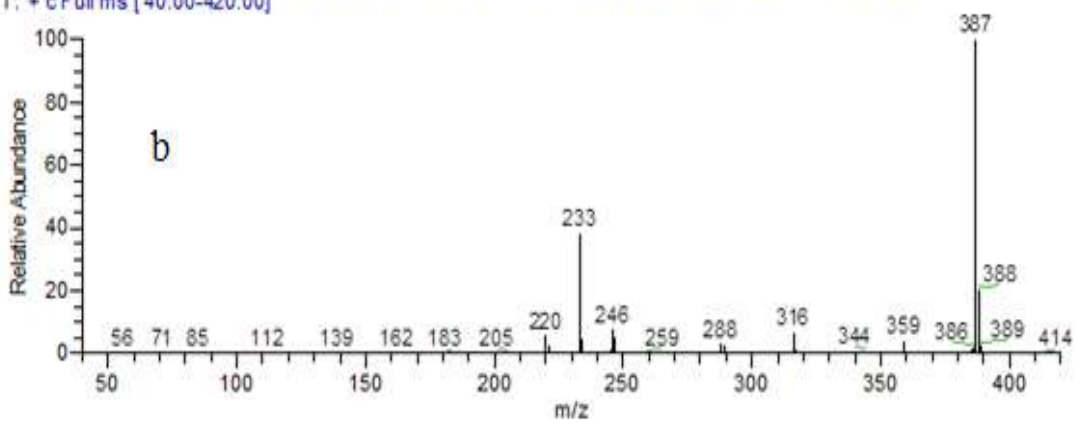

Tera CI DIP 45201101 \#502 RT: 6.92 AV: 1 SB: 465 0.04-6.40, 1.59 NL: $3.99 E 7$

$\mathrm{T}:$ + cFull ms [50.00-450.00]

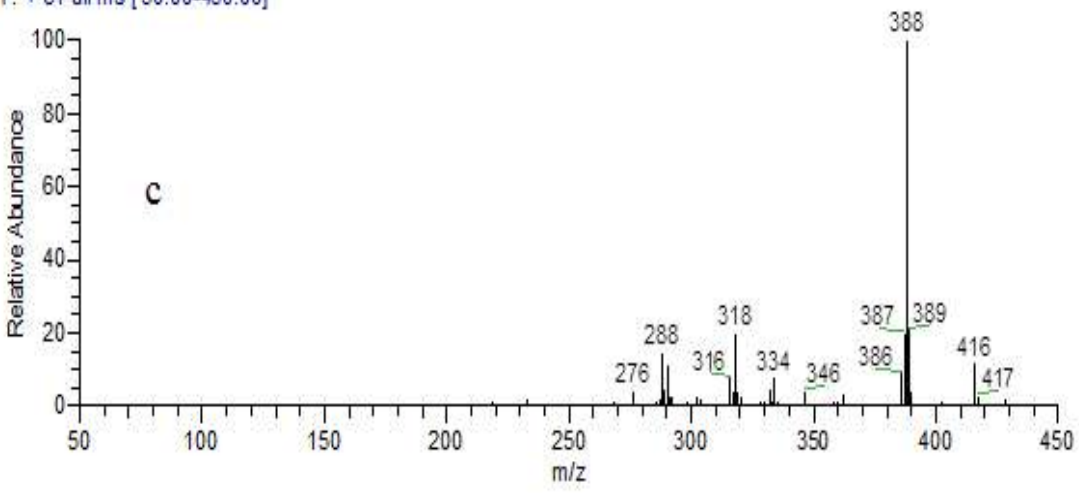

Fig. 4. Comparison of $\mathrm{EI}$ at $(\mathbf{7 0}$ and $15 \mathrm{eV})$ mass spectrum and methane reagent gas CI spectrum of Terazosin drug. Fragmentation is strongly reduced in the CI mass spectrum.

Egypt. J. Chem. 58, No. 3 (2015) 
Mass spectrum of terazosin reveals (Scheme2) three competitive and consecutive fragmentation pathways.

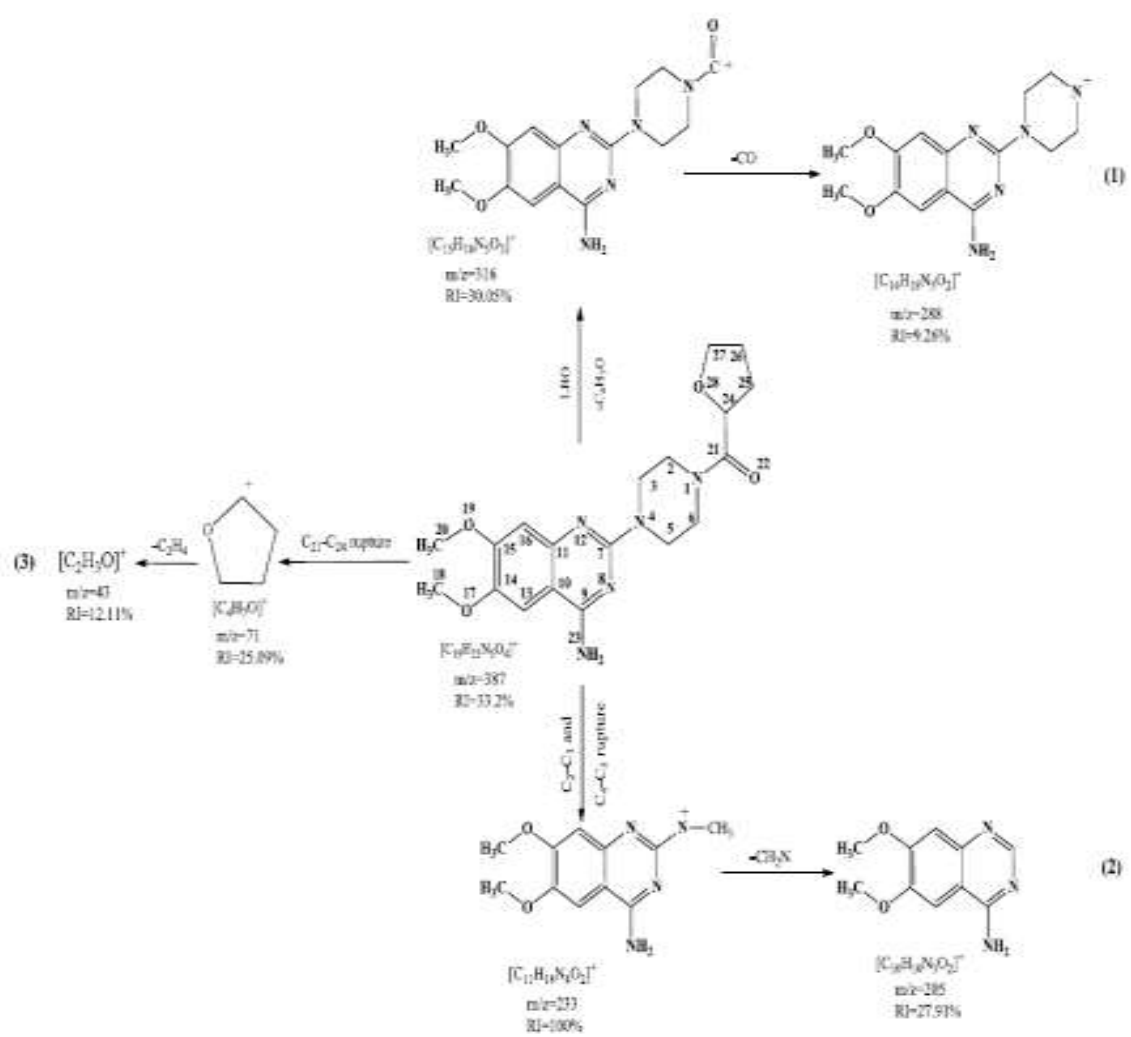

Scheme 2. Fragmentation pathway of principal fragmentation of Tera at $70 \mathrm{eV}$.

The EI spectra of terazosin at $70 \mathrm{eV}$ (Fig. 4a) consist of a wealthy competitive and consecutive fragment ions ranging from $\mathrm{m} / \mathrm{z}=43$ up to molecular ion at $\mathrm{m} / \mathrm{z}=$ 387. The main fragmentation pathways following EI of terazosin at $70 \mathrm{eV}$ are given by the proposed Scheme 2 , in which the signal appeared at $\mathrm{m} / \mathrm{z}=387(\mathrm{RI}=$ $33.20 \%)$ at $70 \mathrm{eV}$ is related to the molecular ion $[\mathrm{M}]^{+}$of general formula $\left[\mathrm{C}_{19} \mathrm{H}_{25} \mathrm{~N}_{5} \mathrm{O}_{4}\right]^{+}$. This molecular ion represents $33.20 \%$ of the base peak at $\mathrm{m} / \mathrm{z}=$ $233(\mathrm{RI}=100 \%)$. Pathway (1) refers to the formation of fragment ions of $\mathrm{m} / \mathrm{z}=$ $316(\mathrm{RI}=30.05 \%)$ and $288(\mathrm{RI}=9.26 \%)$ of the formulae $\left[\mathrm{C}_{15} \mathrm{H}_{13} \mathrm{~N}_{5} \mathrm{O}_{3}\right]^{+}$and $\left[\mathrm{C}_{14} \mathrm{H}_{13} \mathrm{~N}_{5} \mathrm{O}_{2}\right]^{+}$obtained as a result of rupture of bonds $\mathrm{C} 21-\mathrm{C} 24$ and $\mathrm{C} 21-\mathrm{N} 1$ bonds, respectively. Pathway (2) refers to the formation of fragment ions of $\mathrm{m} / \mathrm{z}=$ 233 as a base peak $(\mathrm{RI}=100 \%), \mathrm{m} / \mathrm{z}=205(\mathrm{RI}=27.91 \%)$ of the formulae $\left[\mathrm{C}_{11} \mathrm{H}_{13} \mathrm{~N}_{4} \mathrm{O}_{2}\right]^{+}$and $\left[\mathrm{C}_{10} \mathrm{H}_{10} \mathrm{~N}_{2} \mathrm{O}_{2}\right]^{+}$as a result of rupture of bonds $\mathrm{C} 2-\mathrm{C} 3$ and N4$\mathrm{C} 5$, respectively. Pathway (3) refers to fragment ions of $\mathrm{m} / \mathrm{z}=71(\mathrm{RI}=25.09 \%)$ 
and $\mathrm{m} / \mathrm{z}=43(\mathrm{RI}=12.11 \%)$ of the formulae $\left[\mathrm{C}_{4} \mathrm{H}_{7} \mathrm{O}\right]^{+}$and $\left[\mathrm{C}_{2} \mathrm{H}_{3} \mathrm{O}\right]^{+}$obtained as a result of rupture of bonds $\mathrm{C} 21-\mathrm{C} 24$ and $\mathrm{C} 24-\mathrm{O} 28$, respectively. These fragments are obtained as result of consecutive ruptures of weak bonds as obtained from MOCS (Table 1). In Scheme 2; the ruptured bonds are those unstable as detected by MOCS. These bonds are C21-C24 $(1.540,0.898)<\mathrm{C} 2$ C3 $(1.534,0.964)<\mathrm{C} 3-\mathrm{N} 4(1.488,0.964)<\mathrm{N} 4-\mathrm{C} 5(1.488,0.962)<\mathrm{C} 21-\mathrm{N} 1$ $(1.452,0.991)<\mathrm{C} 7-\mathrm{N} 4(1.366,1.376)<\mathrm{C} 24-\mathrm{O} 28(1.426,0.977)$ respectively; which ordered from the weakest to the strongest depending upon the values of bond length and bond order of the cation form of Tera (Fig. 2b). This order of bond rupture is also correlated with the charge values on atoms of these bonds as given by: C21-C24 $(0.2393,0.0646)<\mathrm{C} 2-\mathrm{C} 3(-0.0846,-0.1731)<\mathrm{C} 3-\mathrm{N} 4(-$ $0.1731,0.3980)<\mathrm{N} 4-\mathrm{C} 5(0.3980,-0.1673)<\mathrm{C} 21-\mathrm{N} 1(0.2393,-0.0825)<\mathrm{C} 7-$ $\mathrm{N} 4(-0.0305,0.3980)<\mathrm{C} 24-\mathrm{O} 28(0.0646,-0.2800)$ respectively. The charge values on bond atoms actually affected both bond length and bond order as a result of repulsive or attractive forces between these atoms. These results may help to identify most of possible metabolites of this drug in vivo system.

On measurement of mass spectra of terazosin by EI at lower power of $15 \mathrm{eV}$ (Fig. 3b) and using CI technique (Fig. 3c) refers to change in nature of the previously obtained main and fragment ions using EI at $70 \mathrm{eV}$. At $15 \mathrm{eV}$ the base peak becomes $\mathrm{m} / \mathrm{z}=387(\mathrm{RI}=100 \%)$ and on using $\mathrm{CI}$ it appears at $\mathrm{m} / \mathrm{z}=388$ $(\mathrm{RI}=100 \%)$ of $[\mathrm{M}]^{+}$of the drug main molecule and the fragment ion of $\mathrm{m} / \mathrm{z}=$ $233(\mathrm{RI}=40 \%)$ which completely disappear on using CI technique. This means that, lowering of energy of the power source increases RI of the drug main molecular ion and makes lot of fragment ions obtained at $70 \mathrm{eV}$ of low RI and / or completely disappeared.

\section{Correlation between TA and MS}

It is important to make a discussion between results of TA and MS of terazosin, to see the behavior of the drug in both techniques. In TA some bonds are thermally unstable in neutral form (Fig. 2a); and consequently decomposed in TG as consecutive pathway. These bonds are C3-C2 $(1.531,0.972)<$ C6-C5 $(1.531,0.973)<\mathrm{C} 7-\mathrm{N} 4(1.423,1.103)$; which ordered from the weakest to the strongest depending upon the values of bond length and bond order of the neutral form of Tera (Fig. 2a) coming from MOCS and as represented in Scheme 1. In EI MS at $70 \mathrm{eV}$ high powers energy leads to more bond ruptures including those ruptured in TA. These bonds are C21-C24 $(1.540,0.898)<\mathrm{C} 2-\mathrm{C} 3(1.534,0.964)$ $<$ C3-N4 $(1.488,0.964)<$ N4-C5 $(1.488,0.962)<$ C21-N1 $(1.452,0.991)<$ C7$\mathrm{N} 4(1.366,1.376)<\mathrm{C} 24-\mathrm{O} 28(1.426,0.977)$ respectively; ordered from the weakest to the strongest depending upon the values of bond length and bond order of the cation form of Tera (Fig. 2b). This comparison shows the agreement to some extent between TA and EI Mass in the proposed fragmentation pathways. Consequently, the effect of such fragmentation on the drug behavior in human body can be expected and also its metabolites can easily be identified. The obtained thermal fragments and mass fragment ions obtained in vitro system are found to be very similar to metabolites obtained in vivo systems ${ }^{(33-35)}$. This

Egypt. J. Chem. 58, No. 3 (2015) 
conclusion reveals the importance of TA and MS vitro systems before going to search for metabolites in vivo system.

\section{Conclusion}

Terazosin drug has great medical importance; it acts as alpha-1-selective adrenoceptor blocking agent. It is used to treat hypertension (high blood pressure) and benign prostatic hyperplasia (enlarged prostate). It causes the blood vessels (veins and arteries) to relax and expand, improving blood flow. Terazosin also relaxes muscles in the prostate and bladder neck, making it easier to urinate. Due to this importance, in the present study, mass spectrometry (MS) and thermal analyses (TA) were used to investigate the fragmentation decomposition pathways of terazosin and confirmed by semi-empirical molecular orbital (MO) calculation, using PM3 procedure on the neutral and the positively charged species of the drug. These calculations included, bond length, bond order, partial charge distribution, ionization energy and heats of formation $(\Delta \mathrm{Hf})$.

The mass spectra and thermal analyses fragmentation pathways were proposed and compared to each other to select the most suitable scheme representing the correct fragmentation pathway of the drug in both techniques. This selection helps understanding of metabolism of the drug in vivo system. Therefore, the successful comparison between MS and TA helps in selection of the proper pathway representing the fragmentation of this drug. This comparison was successfully confirmed by MO-calculation.

\section{References}

1. [Online] available: $\underline{\text { http://www.drugs.com/terazosin.html }}$

2. Ganjali, M.R., Faridbod, F., Larijani, B., Riahi, S., Hosseini, M., Esfahani, E.N. and Norouzi, P., Terazosin potentiometric sensor for quantitative analysis of terazosin hydrochloride in pharmaceutical formulation based on computational study. Int. J. Electrochem. Sci. 5, $200-214$ (2010).

3. Shrivastava, A. and Gupta, V.B., Stability-indicating RP-HPLC method for the simultaneous determination of prazosin, terazosin, and doxazosin in pharmaceutical formulations. Sci. Pharm. 80 (3), 619-631 (2012).

4. Larsen, B.S. and Ewen, C.N.M., "Mass Spectrometry of Biological Materials", Marcel Dekker, New York (1998).

5. Levsen, K., "Fundamental Aspects of Organic Mass Spectrometry", Verlag Chemie, Weiheim, New York. (1978)

6. Zayed, M.A., Fahmey, M.A. and Hawash, M.F., Investigation of diazepam drug using thermal analyses, mass spectra and semi-empirical MO calculations. Spectrochim. Acta A. 61, 799-805 (2005). 
7. Das, K.G. and James, E.P., "Organic Mass Spectrometry", Oxford and IB 11 Publishing Co., New Delhi (1976).

8. Barbas, R., Prohens, R. and Puigjaner, C., A new polymorph of norfloxacin complete characterization and relative stability of its trimorphic system. J. Therm. Anal. Calorim. 89 (3), 687 -692 (2007).

9. Zayed, M.A., Hawash, M.F. and Fahmey, M.A., Structure investigation of codeine drug using mass spectra, thermal analyses and semiempirical MO calculations. Spectrochim. Acta A. 64, 363-71 (2005).

10. Sovizi, M.R., Investigation on decomposition kinetic of naproxen and celecoxib. $J$. Therm. Anal. Calorim. 102, 285-289 (2010).

11. Santos, A.F.O., Basílio, I.D. J.r., de Souza, F.S., Medeiros, A.F.D., Pinto, M.F., de Santana, D.P. and Macêdo, R.O. J., Application of thermal analysis in study of binary mixtures with metformin. Therm. Anal. Calorim. 93 (2), 361-364 (2008).

12. Michalik, K., Drzazga, Z. and Michnik, A., Calorimetric characterization of 2',3'dideoxyinosine water solution. J. Therm. Anal. Calorim. 93 (2), 521-526 (2008).

13. Pourmortazavi, S.M., Hajimirsadeghi, S.S. and Hosseini, S.G., Charaterization of the aluminium /potassium chlorate mixtures by simultaneous TG-DTA. J. Therm. Anal. Calorim. 84, 557-561 (2006).

14. Lever, S.D. and Papadaki, M., Study of condition-dependent decomposition reactions Part I. The thermal behavior and decomposition of 2-nitrobenzoyl chloride. J. Hazard Mater. 115 (1-3), 91-100 (2004).

15. Pourmortazavi, S.M., Hosseini, S.G., Hajimirsadeghi, S.S. and Fareghi, A.R., Investigation on thermal analysis of binary zirconium/oxidant pyrotechnic systems. Combust. Sci. Tech. 180, 2093-2102 (2008).

16. Hosseini, S.G., Pourmortazavi, S.M. and Hajimirsadeghi, S.S., Thermal decomposition of pyrotechnic mixtures containing sucrose with either potassium chlorate or potassium perchlorate. Combust Flame. 141, 322-326 (2005).

17. Fahmy, M.A., Zayed, M.A. and Keshk, Y.H., Comparative study on the fragmentation of some simple phenolic compounds using mass spectrometry and thermal analyses. Thermochim. Acta. 366, 183-188 (2001).

18. Fahmey, M.A. and Zayed, M.A., Phenolic-iodine redox products. Mass spectrometry, thermal analysis and other physicochemical methods of analyses. J. Therm. Anal. Calor, 67, 163-175 (2002).

19. Fahmey, M.A., Zayed, M.A. and El-Shobaky, H.G., Study of some phenolic-iodine redox polymeric products by thermal analyses and mass spectrometry. J. Therm. Anal. Calor, 82, 137-142 (2005).

20. Somogyi, Á., Harrison, A.G. and Paizs, B., Using gas - phase guest - host chemistry to probe the structures of $\mathrm{b}$ ions of peptides. J. Am. Soc. Mass Spectrom. 23, 2055 - 2058 (2012).

Egypt. J. Chem. 58, No. 3 (2015) 
21. Zayed, M.A., Hawash, M.F., Fahmey, M.A. and El-Gizouli, A.M.A., Investigation of ibuprofen drug using mass spectrometry, thermal analyses and semi-empirical molecular orbital calculation. J. Therm. Anal. Calorim. 108, 315-22 (2012).

22. Zayed, M.A., Mohamed, G.G. and Fahmey, M.A., Thermal and mass spectral characterization of novel azo dyes of p-acetoamidophenol in comparison with Hammett substituent effects and molecular orbital calculations. J. Therm. Anal. Calorim. 107, 763-76 (2012)

23. Zayed, M.A., Hawash, M.F. and Fahmey, M.A., Structure investigation of codeine drug using mass spectra, thermal analyses and semiempirical MO calculations. Spectrochim. Acta A. 64, 363-271 (2005).

24. Frag, E.Y.Z., Zayed, M.A., Omar, M.M., Elashery, S.E.A. and Mohamed, G.G., Spectrophotometric determination of carbamazepine and mosapride citrate in pure and pharmaceutical preparations. Arab. J. Chem. 5, 375-382 (2012).

25. Stewart, J.J.P., Optimization of parameters for semiempirical methods I. J. Comput. Chem. 10 (2), 209-220 (2004).

26. Baker, J., An algorithm for the location of transition states. J. Comput. Chem. 7 (4), 385-395 (2004).

27. Stewart, J.J.P. "Software package MOPAC 2000". Fujitsu Limited, Tokyo, Japan (1999).

28. Stanley, S.M., Equine metabolism of buspirone studied by high-performance liquid chromatography/mass spectrometry. J. Mass. Spectrom. 35, 402-407 (2000).

29. Zayed, E.M., Zayed, M.A. and Hindy, A.M.M., Thermal and spectroscopic investigation of novel Schiff base, its metal complexes, and their biological activities. J. Therm. Anal. Calorim. 116, 391-400 (2014).

30. Maryadele, J.O., Patricia E.H., Cherie B.K. and Kristin, J.R. "The Merck Index", $14^{\text {th }}$ ed, Merck \& Co, Inc, Whitehouse Station, NJ, USA, pp. 1574 (2006).

31. Loew, G., Chadwick, M. and Smith, D., Applications of molecular orbital theory in organic molecules. Org. Mass. Spectrom. 7, 1241 (1973).

32. Cooks, R.G., Beynon, J.H., Caprioli, R.M. and Laster, G.R. "Metastable Ions", Elsevier, Amsterdam (1973).

33. EY, O., Bae, S.K., Kwon, J.W., You, M., Lee, D.C. and Lee, M.G., Pharmacokinetic and pharmacodynamics consequences of inhibition of terazosin metabolism via CYP3A1 and/or 3A2 by DA-8159, an erectogenic, in rats. Brit. J. Pharmacol. 151, 24-34 (2007).

34. Cheah, P.Y., Yuen, K.H. and Liong, M.L., Improved high-performance liquid chromatographic analysis of terazosin in human plasma. J. Chromatogr. B. Biomed. Scien. Applicat. 745 (2), 439-443 (2000). 
35. Vincent, J., Dachman, W., Blaschke, T.F. and Hoffman, B.B., Pharmacological tolerance to alpha 1- adrenergic receptor antagonism mediated by terazosin in humans. J. Clin. Invest. 90 (5), 1763-1768 (1992).

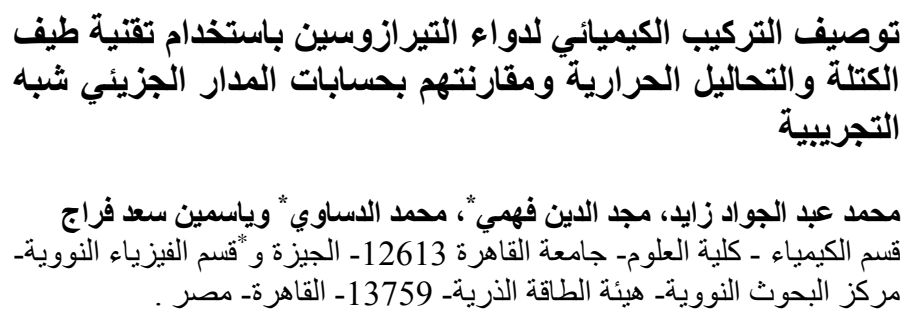

تيرازوسين (الوزن الجزيئي = 387)، هو دواء يعمل على غلق مستقبلات ألفا 1.

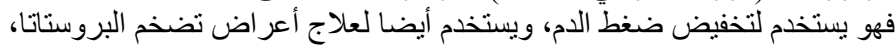

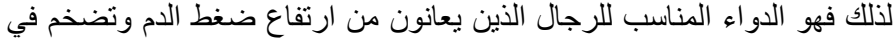

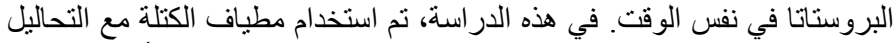

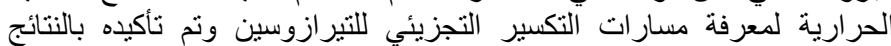

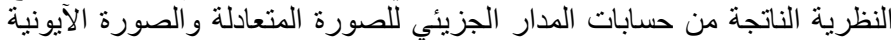

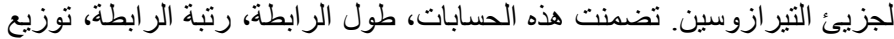

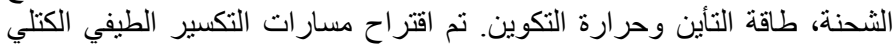

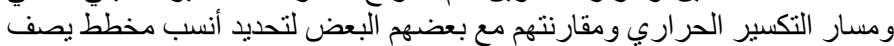

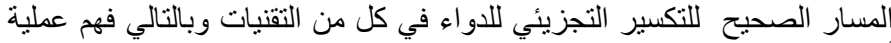

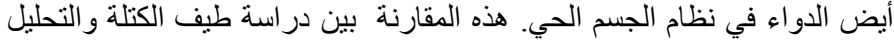

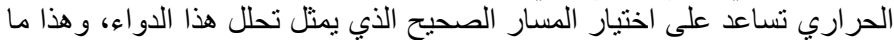
تم تأكيده بنجاح عن طريق حسابات المدار ات الجزئئية. 